\title{
Women Security System using IoT
}

\author{
Suma K.V, V.Simran Parveen, Sucheta, Kavya Jadav M, Sanjana M
}

\begin{abstract}
In today's world, women have to undergo among various difficult situations and have to prove themselves every time in all critical conditions. Here, we are focusing on a scenario where, a woman is walking alone in lonely places faces the attack either from front or back during day time or night. Hence we have designed a system having a quick responding mechanism to help out the women in trouble. The proposed system is more like a safety system in case of emergency. This type of an idea plays a crucial role towards ensuring women safety automatically in the fastest way possible. Smart wearable devices can be used to screen physical signs of panic and anxiety through the wearer's heart rate and other mechanism to trigger responses like alarming nearby people and emergency contacts. Such smart security solutions for women using IoT can ensure quick responses to emergencies and prevent potentially shocking experiences for women.
\end{abstract}

Keywords - Smart Sling bag, IoT, woman security, alert message, registered mobile number.

\section{INTRODUCTION}

Every girl has a haunting thought about when they will be able to move freely on the streets even in odd hours without worrying about their security. Women harassments are increasing day by day. Even though, there are many existing systems for security purpose need of advanced smart security system is increased. Technology is the best way to achieve it. That's the reason to develop this project that can act as a rescue device and protect at the time of danger. We can make use of number of sensors to precisely so that they never feel helpless while facing such social challenges. An advanced smart system is built that can detect the location of the woman that enables to take action based on electronic gadgets like GPS receiver, GSM, pulse rate sensor, detect the live situation of the women in critical situations. The heartbeat of a person in such situations is normally higher which helps make decisions to detect the abnormal motion of the women while she is victimized. The ultrasonic sensors are used to detect any person coming very close to the woman. Nowadays though there are many apps evolved for women safety via smart phone it is activated only by a touch or one click or shake. It is not possible to have mobiles on our hand in all circumstances. Focusing on the security of a woman, we are implementing a wearable device in the form of a Smart Sling bag which

Revised Manuscript Received on July 22, 2018.

Dr. Suma K. V, Department of ECE, Ramaiah Institute of Technology, Bengaluru, India,sumakv@ msrit.edu

Kavya Jadav M, Department of ECE, Ramaiah Institute of Technology, Bengaluru, India, kavyajadav7@gmail.com

$\mathrm{V}$ Simran Parveen, Department of ECE, Ramaiah Institute of Technology, Bengaluru, India, simranparveen1822@gmail.com

Sanjana M, Department of ECE, Ramaiah Institute of Technology, Bengaluru, India, sanjana12hemu@gmail.com

Sucheta, Department of ECE, Ramaiah Institute of Technology, Bengaluru, India, suchetakulkarni777@gmail.com includes detection of threat, communicating and a simple defense. This system can perform a real time monitoring of desired area and detect the violence with good accuracy..

\section{SYSTEM DESCRIPTION}

\section{A. Transmitter Section}

This project presents the women security system which consists of different sensors and modules. It is interconnected with an alarm system which alerts the people nearby. This system has the GPS module to track the location of the women and a GSM module to send an alert message along with live location. There is a pulse sensor and two ultrasonic sensors, one at the back and the other, in the front. If any person tries to come very close to her, the sensor senses the situation and sends it to the microcontroller. The microcontroller processes all the information and if any untoward situation occurs, a message is sent to the registered mobile number along with the location details. Also an alarm is triggered to alert the people around indicate someone is in trouble. This system is automatic. But due to some unexpected problem, if the sensor fails to detect the situation, a switch button can be pressed so that, she can press it when she is in danger. Also, sometimes if by mistake there is false trigger, there is another switch which stops the whole of the process. The flash light circuit helps in simple defense by blurring the eyes of the culprit.

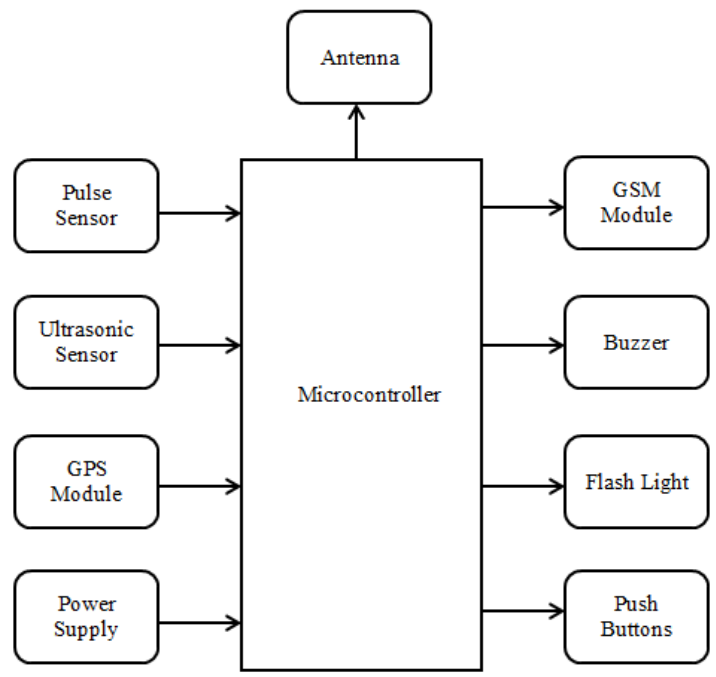

\section{A.Receiver Section}

The microcontroller will send a signal to the GSM module which in turn sends an alert message saying, "Please Help...I am in trouble!!" to the pre-stored contact in the system. Also, the live location of the woman is also sent along with an alert message. 


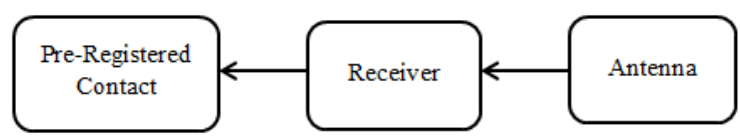

Fig 2: Receiver Section

\section{Scenario 1:}

When a woman is walking in a lonely place, if a person tries to attack her either from front or back, the ultrasonic sensor senses the situation and sends the signal to the microcontroller. The microcontroller processes the information and triggers an alarm to alert the nearby people. Also, a message is sent to the pre-registered contact along with location details.

\section{Scenario 2:}

When a woman is walking in a lonely place, if a person tries to attack her either from front or back and the ultrasonic sensor fails to sense the situation, the woman herself can press the panic button which sends the signal to the microcontroller which triggers an alarm to alert the nearby people. Also, a message is sent to the pre-registered contact along with location details.

\section{Scenario 3:}

When a woman is walking and if any false trigger occurs which triggers an alarm, the woman can press a button, which will stop the process.

\section{MODULES USED}

1. Microcontroller

- It takes input signals from various sensors and gives the output signals to various modules to carry out the process.

2. Pulse Sensor

- Pulse sensor is based on the principle of photoplethysmography (PPG) which is a non-invasive method of measuring the changes in blood volume using an optical source and a detector.

- When a sensor is placed on the fingertip, it is illuminated by the IR light coming from the LED and the photo sensor receives the light from the skin tissue which is placed on the other side.

- A specific threshold is maintained. During critical situations, the heart rate is normally high. When the sensor exceeds the threshold readings, a signal is sent to the microcontroller.

- The digital pulses are given to a microcontroller for calculating the heat beat rate, given by the formula: $B P M=60 \times f$

Where, BPM is Beats per minute and $\mathrm{f}$ is the pulse frequency. Total Distance $=\frac{343 \times \text { Time of High }(\text { Echo }) \text { Pulse }}{2}$

Fig 3: Graph of absorption of human blood vs wavelength of light. "SFH 7050 - Photoplethysmography Sensor", Hubert Halbritter, Rolf Weber, Stefan Strüwing, June, 2014

\section{Ultrasonic sensor (HCSR-04)}

- An ultrasonic sensor uses a transducer to send and receive ultrasonic pulses that relay processes the information accordingly. It then

back information about an object's proximity. High-frequency sound waves reflect from boundaries to produce distinct echo patterns.

- A specific threshold is maintained for the ultrasonic sensors detection. If any person comes very close to the woman crossing the threshold, the sensor sends an input signal to the microcontroller.

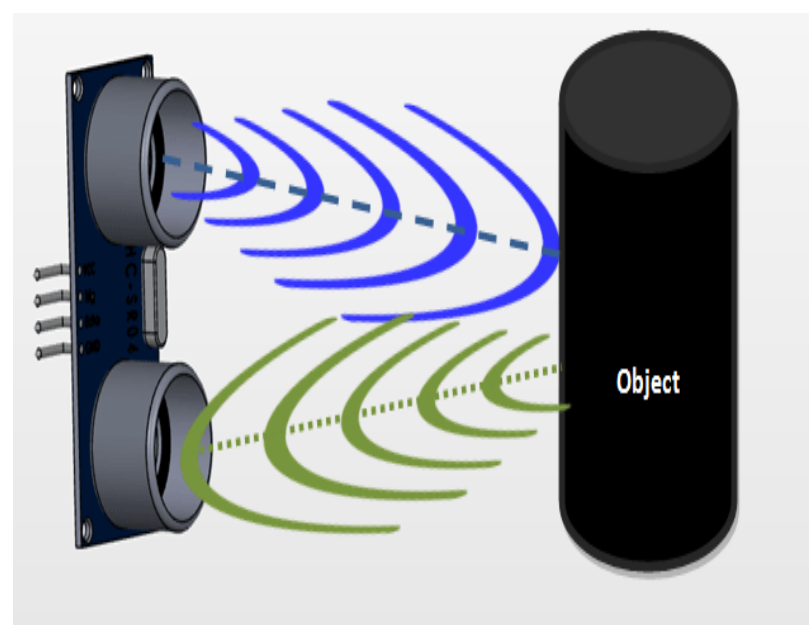

Fig 4: Ultrasonic Sensor Working (HC SR04 Working Pin-out Datasheet)

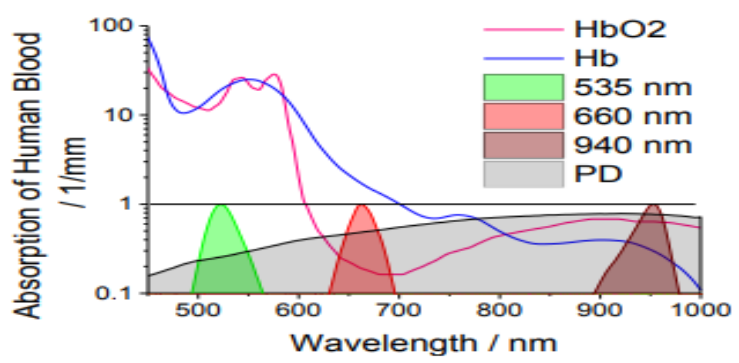

We know that,

\section{Distance $=$ Speed $\times$ Time}

The speed of sound waves is $343 \mathrm{~m} / \mathrm{s}$. So,

d. Total Distance $=\frac{343 \times \text { Time of High(Echo)Pulge }}{2}$

e. Total distance is divided by 2 because signal travels from HC-SR04 to object and returns to the module HC-SR-04.

4. GSM and GPS Modules

- The GSM module used here is the GSM Sim800L. It is used to send the alert message to the pre-stored contact during untoward situations.

- The operating voltage is about $3.4 \mathrm{~V}$ to $4.4 \mathrm{~V}$. It is provided with a power supply of $3.7 \mathrm{~V}$ with a LiPo Battery. 
- The GPS module is used to track the live location of the woman. It sends the signal to the microcontroller which in turn sends the location details to the pre-registered contact through the GSM module.

\section{Buzzer}

- Buzzer is interfaced with the microcontroller which is used to alert the nearby people during untoward situations.

- It gives a loud screechy sound so that people nearby can be indicated that something wrong is going on near-by.

\section{Flash Light Circuit:}

- The LEDs are used in a flash circuit for simple defence mechanism.

- It is interfaced with the microcontroller which flashes the light continuously for few seconds which blurs the eyes of the culprit.

\section{RESUlts}

Ultrasonic Sensor Readings:

The readings were taken from different distances in different directions to calculate the speed of the attacker. Taking this into consideration, the threshold for the ultrasonic sensor was determined. This threshold is given to the ultrasonic sensors both at the front and the back.

\begin{tabular}{|c|c|c|c|c|}
\hline $\begin{array}{c}\text { Sl } \\
\text { No. }\end{array}$ & $\begin{array}{c}\text { Position1 } \\
(\mathbf{c m})\end{array}$ & $\begin{array}{c}\text { Position } \\
\mathbf{2}(\mathbf{c m})\end{array}$ & Direction & $\begin{array}{c}\text { Speed } \\
(\mathbf{m} / \mathbf{s})\end{array}$ \\
\hline 1 & 265 & 112 & Towards the woman & 15.3 \\
\hline 2 & 117 & 87 & Towards the woman & 3 \\
\hline 3 & 25 & 7 & Towards the woman & 1.8 \\
\hline 4 & 257 & 5 & Towards the woman & 25.2 \\
\hline 5 & 256 & 96 & Left to Right & 16 \\
\hline 6 & 111 & 8 & Left to Right & 10.3 \\
\hline 7 & 255 & 95 & Right to Left & 16 \\
\hline
\end{tabular}

Table 1: Ultrasonic Sensor

The prototype for women safety device is as shown in the Fig 5. The signals from the pulse sensor and the ultrasonic sensors are detected successfully and sent to the microcontroller. When these sensors cross the threshold values, the alarm triggers.

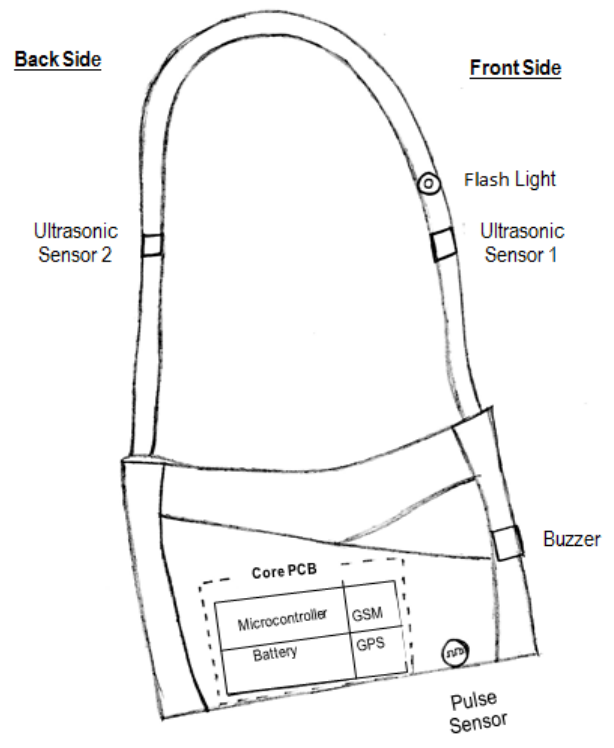

Fig 5: Smart Sling Bag

The GPS turns on and traces the location of the woman and with the help of GSM module, the microcontroller sends the message "Please Help...I am in trouble!!" along with the location to the registered mobile number as shown in Fig.6 and Fig.7
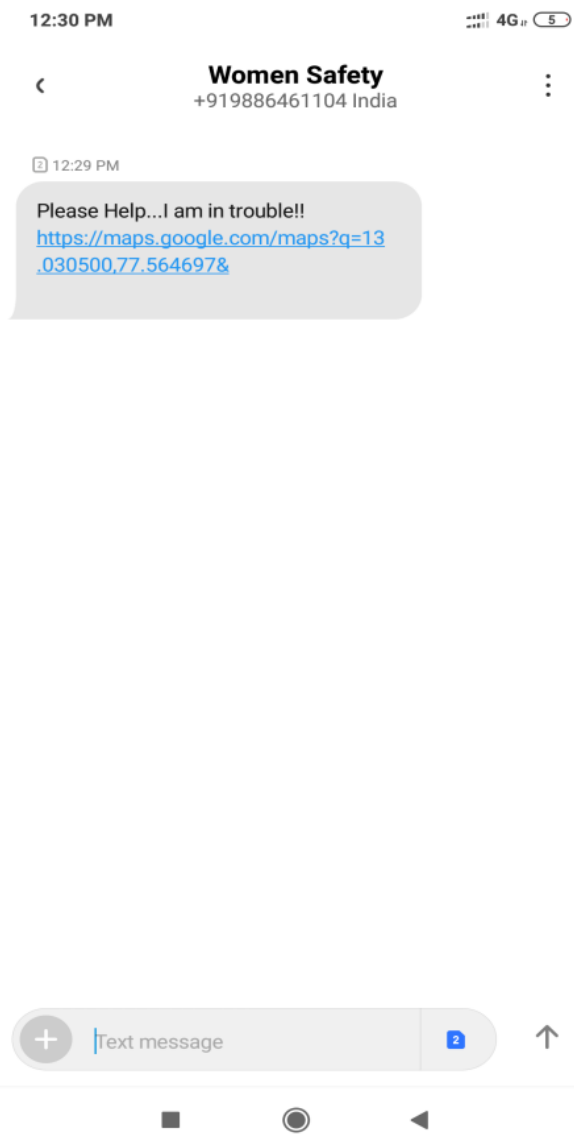

Fig 6: Message Received to the Registered Mobile Number 


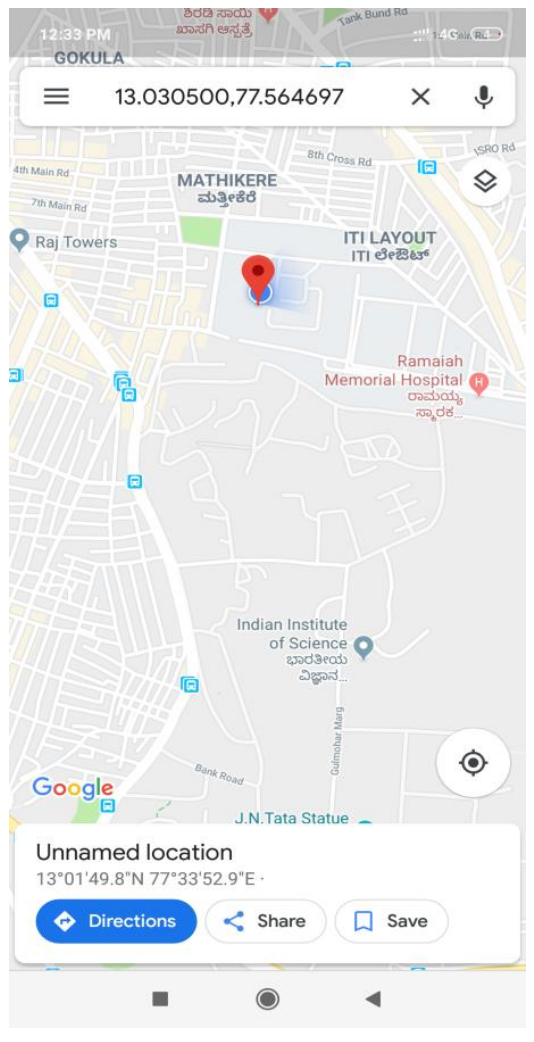

Fig 7: Location of the woman

\section{ACKNOWLEDGMENT}

The authors would like to express their gratitude and respect towards Shri. Krishna Kumar M, Department of CEDT and CSA, Indian Institute of Science, Bangalore for timely advice, suggestions and regular assistance in our project work and also to Ramaiah Institute of Technology, Bangalore for the logistical support provided during the completion of the study.

\section{REFERENCES}

1. Kalpana Seelam, K. Prasanti, "A Novel Approach to Provide Protection for Women by using Smart Security Device" in Proceedings of the Second International Conference on Inventive Systems and Control (ICISC), IEEE, 2018, pp. 351-357.

2. Shika Elizabeth Sam, Suma K. V, "Wearable Biomedical Device using Telemedicare and Telereporter", in International Confrence on Wearable Technologies (ICOWT'17), June 26-27, 2017.

3. A Helen, M. Fathima Fathila, R. Rijwana, Kalaiselvi .V.K.G, "A Smart Watch for Women Security based on IoT concept 'Watch Me' ", in Second International Conference on Computing and Communications Technologies (ICCCT'17), IEEE, 2017, pp. 190-194.

4. Mohamad Zikriya, Parmeshwar M. G, Shanmukayya R. Math, Shraddha Tankasali, Dr. Jayashree D Mallapur, "Smart Gadget for Women Safety using IoT (Internet of Things)", in International Journal of Engineering Research \& Technology (IJERT), 2018, Volume 6, Issue 13, pp: $1-5$.

5. Prof. R. A. Jain, Aditya Patil, Prasenjeet Nikam, "Women's safety using IOT", in International Research Journal of Engineering and Technology (IRJET), 2017, Volume 05, Issue 05, pp: 2336-2338.

6. B. Umadevi, Dr. Eshwaran, Dr. Manoharan, "Women Security Solution using IoT" in International Journal of Pure and Applied Mathematics (IJPAM), 2018, Volume 119, No.10, pp: 1871-1874.

7. Shirly Edward A, Vijayakumari S. G, Bhuvaneswari M. S, "GSM Based Women's Safety Device", in International Journal of Pune and Applied Mathematical (IJPAM), 2018, Volume 119, No.15, pp: 915-920.
8. Jesudoss, Y. Nikhila, T. Sahithi Reddy, "Smart Solution For Women Safety Using Iot", in International Journal of Pune and Applied Mathematical (IJPAM), 2018, Volume 119, No.12, pp: 43-49.

9. Prof. Kshitija V. Shingare, Miss. Ashwini P. Thaware, "A Safety Device for Women's Security Using GSM/GPS", in International Journal on Research and Innovation Trends in Computing and Communication (IJRICC), 2017, Volume 5, Issue 4, pp: 05-07.

10. Piyush Kumar Verma, Arpit Sharma, Dhruv Varshney, Manish Zadoo, "Women Safety Device with GPS, GSM and Health Monitoring System", in International Research Journal of Engineering and Technology (IRJET), 2018, Volume 5, Issue 03, pp: 941-943. 